\title{
Production of Plastic Cement Concrete from PVC Waste
}

\author{
Iram Juma Ibrahim Al Kindi ${ }^{1}$, M. Geetha Devi ${ }^{1^{*}}{ }^{\complement}$, Mohammed Al Abri ${ }^{2}$, Soleen Al Hasan ${ }^{3}$, Eman \\ Muhye Adeen Muhye Al Hatali ${ }^{3}$, Aravind $\mathbf{N}^{3}$
}

${ }^{1}$ Mechanical \& Industrial Engineering Department, National University-College of Engineering, Oman

${ }^{2}$ Department of Nanotechnology, Sultan Qaboos University, Oman

${ }^{3}$ Dept of Civil Engineering, National University-College of Engineering, Oman

Email: geethadevi@nu.edu.om

Received: 10 June 2021; Revised: 21 July 2021; Accepted: 23 September 2021

\begin{abstract}
The disposal of plastic wastes into the environment is a serious concern due to its limited biodegradability and production in excess quantity. The accumulation of enormous volumes of plastic waste is considered to be a major pollution problem and it is essential to find an alternate method to address such issues in an environmental-friendly and cost-effective way. The current research focused on the production of plastic cement concrete from waste polyvinyl chloride (PVC) generated from a polymer processing industry in varying proportions, and to modify the concrete properties. Polyvinyl chloride was partially replaced with Ordinary Portland Cement (OPC) by varying its compositions from $15 \%$ to $35 \%$ by weight (i.e. $15 \%, 20 \%, 25 \%, 30 \%$ and $35 \%$ OPC). The curing period was kept for 7 days after casting process. The produced plastic cement concrete was tested for compressive strength through Universal Testing Machine (UTM). Density and water absorption tests were also carried out on hardened concrete to assess the application of plastic cement concrete as a building material. The other characterization techniques employed are Fourier Transform Infrared Spectroscopy (FTIR) and X-Ray Diffraction (XRD) analyses. It was observed that up to $15 \%$ by weight of polyvinyl chloride could be replaced with OPC which exhibited higher compressive strength (19.25 MPa) compared to other mix proportions. A maximum density of $2.051 \mathrm{~g} / \mathrm{cm}^{3}$ was obtained at a concrete mix composition corresponding to $25 \%$ replacement. The maximum water absorption percentage $(5.86 \%)$ was observed at $35 \%$ plastic waste replacement. The studies demonstrate that the waste plastic material is considered to be a cost-effective, viable and sustainable way of reducing the environmental pollution.
\end{abstract}

Keywords: non-biodegradability, concrete mix, disposal, plastic cement concrete, Portland cement, polyvinyl chloride

\section{Nomenclature}

$\begin{array}{ll}\text { PE } & \text { Poly Ethylene } \\ \text { PVC } & \text { Poly Vinyl Chloride } \\ \text { PP } & \text { Poly Propylene } \\ \text { EP } & \text { Expoxide } \\ \text { PUR } & \text { Polyurethane } \\ \text { PF } & \text { Phenol Formaldehyde }\end{array}$

Copyright (C2021 M. Geetha Devi, et al

DOI: https://doi.org/10.37256/fce.222021984

This is an open-access article distributed under a CC BY license

(Creative Commons Attribution 4.0 International License)

https://creativecommons.org/licenses/by/4.0/ 


$\begin{array}{ll}\text { OPC } & \text { Ordinary Portland Cement } \\ \text { UTM } & \text { Universal Testing Machine } \\ \text { XRD } & \text { X Ray Diffraction } \\ \text { FTIR } & \text { Fourier Transform Infrared Spectroscopy } \\ \text { ACI } & \text { American Concrete Institute }\end{array}$

\section{Introduction}

The consumption of plastics in the world has increased to 5 million tons every year. Consequently, a huge amount of plastic is discarded as waste, which leads to environmental and health issues due to the lack of environmental-friendly disposal methods. Environmental and Civil/Construction engineers and researchers are trying to find appropriate remedial measures to address this issue by adopting eco-friendly methods for the disposal and recycling of waste. The majority of the countries is employing land filling method for disposing of plastic wastes, which is harmful to the environment. ${ }^{1}$ The usage of plastic and its composites is still intensifying quickly due to their easy-availability, low-cost and simple processing techniques. Therefore, a large quantity of waste plastics are being dumped into the atmosphere, thereby experiencing major challenges in the disposal techniques. ${ }^{2}$ The disposal of plastics by landfills results in the contamination of ground water with the generation of methane gas, which is one of the main causes of global warming. The recent statistics indicate that nearly 5 trillion tons of toxic plastic waste materials are being dumped into the ocean, posing a threat to marine life, animal and birds. One of the eco-friendly methods employed in the disposal of highdensity polyethylene waste was to use the combination of polyethylene waste and ordinary Portland cement. The outcome of the study demonstrates that the production of plastic cement concrete using $60 \%$ polyethylene waste and $40 \%$ OPC generated good quality cement concrete. Quarry dust and polyvinyl chloride powder as a fine aggregate were added into the concrete mix and the results illustrated a reduction in the production cost and an increase in the strength and durability of concrete. The best result after two processing stages indicated a 20\% replacement of polyvinyl chloride. These results showed an increase in the compressive strength and elastic modulus of the concrete. ${ }^{3,4}$ Oil Refinery waste was considered as an additive in concrete mix to enhance the mechanical and physical properties. The research results revealed that the presence of the additives will enhance the resilience of the concrete and increase its density, frost resistance, porosity, compressive strength, and water absorption capability. The study supported lowering the unit cost, limiting waste generation and reusing the same in an eco-friendly way. ${ }^{5}$ The catalysts from the fluid catalytic cracking unit are mixed with cement to enhance the compressive strength of concrete and the study indicates a rise in compressive strength. ${ }^{6}$ A number of studies have been carried out to enhance the properties of self-compacting concrete using varieties of fly ash, slag, and fumed silica coupled with recycled course aggregates. ${ }^{71}$ However few studies have been reported on the application of natural pozzolana in the form of volcanic ash (VA) for the production of vibrated cement concrete VCC as well as self-compacting concrete SCC. ${ }^{12-14}$

Due to the larger demand for plastics for various applications, many polymer processing industries face difficulties in disposing of huge volumes of waste materials. Dumping plastic waste into the environment by domestic and landfills is considered a major challenge. The sustainability of most of the polymer processing industries depends on the selection of recycling and reuse options and hence, reusing plastic wastes can be helpful to solve major environmental issues and also can limit the wastage of resources. ${ }^{15-17}$ The key advantage of plastic recycling in concreting is to enhance the tensile strength, creep strength, chemical resistance, and shrinkage during dry. ${ }^{2}$ Sustainable and green techniques can minimize the adverse effects of greenhouse gas emissions by maximizing profit and also protecting the environment. ${ }^{18}$ The compressive strength and workability of the concrete were diminished due to the changing proportions of concrete mix with plasticizers. Application of polyethylene terephthalate waste as a partial replacement to cement showed a reduction in compressive strength and weight of the concrete. ${ }^{19,20}$ Also if the proportions of polyethylene terephthalate exceed $50 \%$ by volume of sand, then there was a decrease in the density and compressive strength of concrete. ${ }^{21}$ The main approach to suppress carbon dioxide emission is recycling and reuse of building materials and use of environmentally friendly and low-cost substances. ${ }^{22,23}$

Aluminium powder and plastic wastes are commonly mixed with concrete for the preparation of lightweight concrete Aravind and Abdulrehman ${ }^{24}$, Based on the study conducted by Sifatullah et al. ${ }^{25}$, plastic wastes can be used as a substitution material (plastic aggregate) or an additional material (plastic fibers) to mortar/concrete mixtures. A recent 
study conducted by Castillo et al. ${ }^{26}$ reported that synthetic aggregate manufactured from plastic waste can be used to prepare lightweight concrete. Mustafa et al. ${ }^{27}$ have demonstrated an experimental and numerical investigation of the influence of partial replacement of coarse aggregates by plastic waste. Ravikumar et al. ${ }^{28}$ selected polyvinyl chloride (PVC) to replace the coarse aggregate in the concrete to increase its strength. The replacement percentages were 15\%, $20 \%$ and $25 \%$, and tested for three different time periods of 7 days, 14 days and 28 days. It was observed that the higher compressive strength for the concrete at $20 \%$ after the periods of 7 days and 14 days, with $22.22 \mathrm{~N} / \mathrm{mm}^{2}$ and $25.88 \mathrm{~N} /$ $\mathrm{mm}^{2}$ respectively. Therefore, the partial replacement of coarse aggregate with PVC showed an increase in compressive strength and split tensile of concrete with the increase in PVC percentage. Kolhapure et al. ${ }^{29}$ studied the capability of making eco-friendly concrete by replacing the fine aggregate with waste bottles made of polyethylene terephthalate. The replacing percentages that have been studied are $1 \%, 1.5 \%, 2 \%, 2.5 \%, 3 \%, 4 \%, 5 \% \& 6 \%$, and the curing period was 28 days. The results of the study showed an increase in the compressive strength at $4 \%$ replacement and an increase in split tensile and flexural strength at $2 \%$ replacement. Shadrack et al ${ }^{30}$ studied the possibility of mixing the oil sludge with demolition waste as a building material in Tanzania. The Aqua regia digestion extraction method was employed to determine the elemental concentration of the oil sludge, where 3 parts of hydrochloric acid and 1 part of nitric acid have been used. The resulting sludge was mixed with cement and water to form the cement paste. The test result showed an increase in the compressive strength on the cement and the suggested solution helped Tanzania to reduce the area needed to dump the waste oil sludge. Therefore this research focus on the prospects of utilizing plastic waste discarded from polymer processing industries as a construction material in a technologically feasible, economically viable, ecofriendly, and socially acceptable manner. The study also focused on the effect of replacing cement with powdered polyvinyl chloride waste at different compositions on enhancing the mechanical properties.

\section{Experimental details}

\subsection{Materials}

Waste Polyvinyl chloride powder was collected from a leading polymer processing company in Oman. PVC powder offers excellent corrosion resistance, good fatigue and wears resistance. The lightweight, non-toxic nature, better resistance to stain, excellent impact resistance, and high tensile strength properties of PVC have attracted considerable attention in the preparation of plastic cement concrete. The fine aggregate, coarse aggregate, and OPC were purchased locally. The concrete mixing process was carried out using a mixer machine. 100T UTM was used to test the compressive strength of concrete. Grain size and crystalline structure was detected using X-Ray Diffraction (Rigaku, and Mini Flex 600), Fourier Transform Infrared Spectroscopy (FTIR- Frontier is Perkin Elmer's) analysis was performed to determine the functional groups present in the sample. The concrete mix was prepared by mixing different proportions of fine aggregate, coarse aggregate, and water as indicated in Table 1. The mix design was prepared using grade $\mathrm{C} 30$ normal concrete with a ratio 1:1.7:2.34 as per American Concrete Institute (ACI) code. The required quantity of materials for $\mathrm{C} 30$ concrete mix is given in Table 1.

Table 1. The amount of concrete ingredients required for C30 Mix

\begin{tabular}{|c|c|c|c|c|}
\hline Ingredients & Cement & Fine aggregate & Coarse aggregate & Water \\
\hline Quantities, kg & 410 & 699.48 & 960 & 205 \\
\hline Ratio by weight & 1 & 1.7 & 2.34 & 0.5 \\
\hline Size/Properties & Specific gravity $=3.15$ & Maximum size $=5 \mathrm{~mm}$ & Maximum size $=20 \mathrm{~mm}$ & $\begin{array}{c}\mathrm{TDS}=400 \mathrm{ppm} \\
\mathrm{pH}=7.0\end{array}$ \\
\hline
\end{tabular}

The partial replacement compositions of cement by polyvinyl chloride (PVC) are 15\%, 20\%, 25\%, 30\%, and 35\% by weight (Table 2). The control mix containing 0\% polyvinyl chloride (PVC) was used as a reference for comparison 
purpose. Three cubes with the total volume of $0.01 \mathrm{~m}^{3}$ were used as a control mix to minimize the errors. In order to avoid cracking or breaking of the cubes, the inner surface of the moulds are coated with oil and hence the concrete mixes can be easily demoulded after the drying process.

The mix design was prepared as per the proportions shown in Table 2. The required weights of all materials are transferred to the concrete mixer machine and mixed for 1 minute followed by manual mixing to get a homogenous concrete mix. The casting of the mould was carried out by filling the three moulds with the concrete mix followed by compacting the concrete and allowed to dry for 24 hours. The concrete mixes are taken out from the mould after drying for a specified period and soaked in water for 7 days (Figure 1) for curing and to examine their stability. Curing is one of the important steps to enhance the strength of the concrete by protecting it from moisture loss during hydration. The hydration of concrete will augment the strength and reduce its permeability and thermal cracks. During the first 7 days, the tri-calcium silicate present in cement is responsible for altering the strength. The hydration reaction releases hydroxide ions, calcium ions, and hence liberates a high amount of heat. As a result, the value of $\mathrm{pH}$ increased rapidly to 12.0, due to the presence of alkaline hydroxide $\left(\mathrm{OH}^{-}\right)$ions.

Table 2. Partial replacement percentages

\begin{tabular}{cccccccc}
\hline & & \multicolumn{5}{c}{ Plastic waste replacement } \\
\cline { 3 - 7 } Batch Design & Weight per cubic meter & $\begin{array}{c}0 \% \\
\text { (Control Mix })\end{array}$ & $15 \%$ & $20 \%$ & $25 \%$ & $30 \%$ & $35 \%$ \\
\hline Cement $(\mathrm{kg})$ & 410 & 4.1 & 3.49 & 3.28 & 3.08 & 2.87 & 2.67 \\
Plastic waste (kg) & 0 & 0 & 0.62 & 0.82 & 1.03 & 1.23 & 1.44 \\
Fine aggregate (kg) & 699.48 & 7 & 7 & 7 & 7 & 7 & 7 \\
Coarse aggregate (kg) & 960 & 9.6 & 9.6 & 9.6 & 9.6 & 9.6 & 9.6 \\
Water (lit.) & 205 & 2.05 & 2.05 & 2.05 & 2.05 & 2.05 & 2.05 \\
\hline
\end{tabular}

The chemical transformation taking place during the curing process is shown in the stochiometric equation (1).

$$
2(\mathrm{CaO})_{3}\left(\mathrm{SiO}_{2}\right)+7 \mathrm{H}_{2} \mathrm{O} \rightarrow(\mathrm{CaO})_{3}\left(\mathrm{SiO}_{2}\right)_{2} 4\left(\mathrm{H}_{2} \mathrm{O}\right)+3 \mathrm{Ca}(\mathrm{OH})_{2}+173.6 \mathrm{~kJ}
$$

\subsection{Density and water absorption test}

After the curing, the cubes are immediately removed from the water for measuring the wet weight $\left(m_{w}\right)$. Then the cubes are taken out and kept for 24 hours to dry it completely, and measure the dry weight $\left(m_{d}\right)$. Figure 1 and Figure 2 represent the images of wet and dry concrete cubes.

The percentage water absorption was calculated using equation (2).

$$
W_{A b s}, \%=\frac{m_{w}-m_{d}}{m_{d}} \times 100
$$

Where,

$W_{A b s}, \%=$ Water absorption percentage;

$m_{w}=$ total wet mass of the cubes in $\mathrm{kg}$;

$m_{d}=$ total dry mass of the cubes $\mathrm{kg}$. 


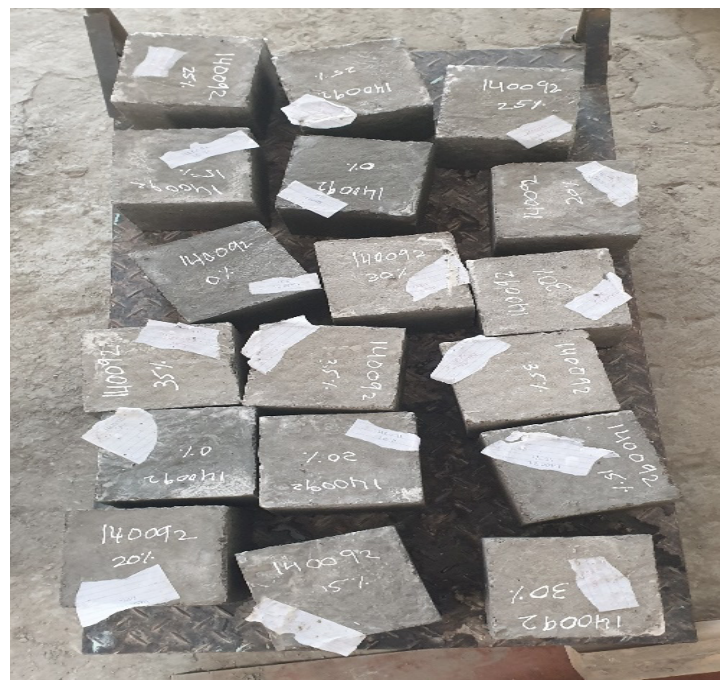

Figure 1. Wet concrete

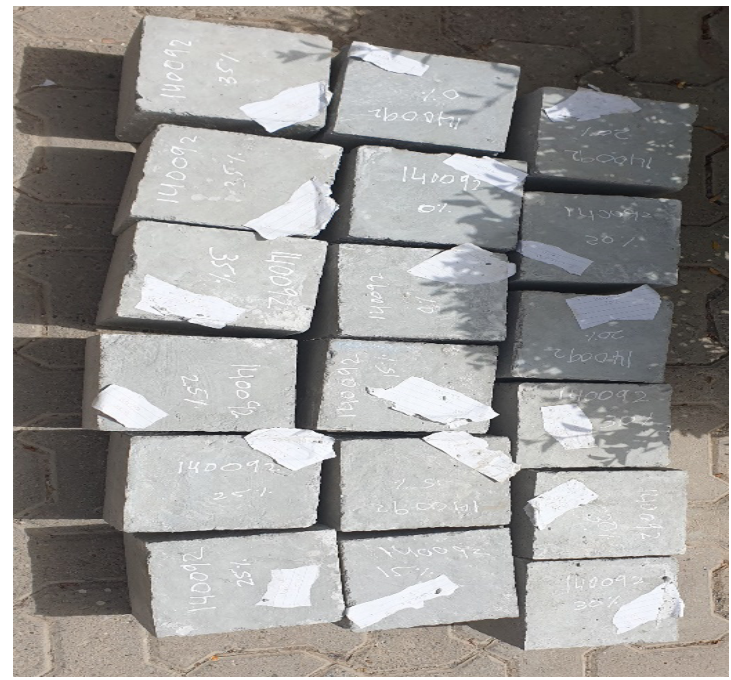

Figure 2. Completely dried concrete cubes

\subsection{Compressive strength test}

The compressive strengths of the cubes are tested using Universal Testing Machine (UTM) as shown in Figure 3. The compressive strength is calculated using equation 3 .

$$
\text { The compressive strength }=\frac{P \times 10^{3}}{A}, M P a
$$

Where,

$P$-Maximum compressive force applied to the concrete cube at which it breaks in $\mathrm{kN}$; $A$-Cross sectional area in $\mathrm{m}^{2}$.

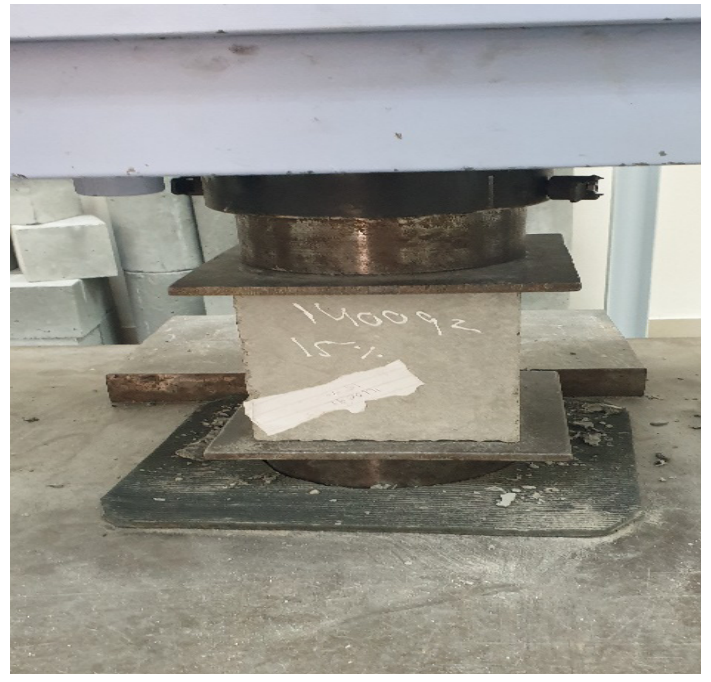

Figure 3. Compressive strength test on concrete 


\section{Results and discussion}

The production of plastic cement was facilitated by partial replacement of the Portland cement with the polyvinyl chloride (PVC) in cement concrete. The partial replacement of PVC would help to regulate the concrete properties and also to reduce the cost of production. The polyvinyl chloride (PVC) and concrete mix of different proportions were tested using X-Ray Diffraction (XRD) and Fourier Transform Infrared spectroscopy (FTIR). The compressive strength of the resulting product was tested using Universal Testing Machine (UTM).

\subsection{Concrete density}

The wet and dry densities of the produced plastic cement were estimated and the results are expressed in Table 3 . The results indicate that there is a decrease in the density values.

When the plastic waste, Polyvinyl chloride was partially replaced with Ordinary Portland Cement (OPC) by varying its compositions from $15 \%$ to $35 \%$ by weight, the density of concrete is decreasing in trend. When compared to the control specimen, the dry densities of concrete with $15 \%, 20 \%, 25 \%, 30 \%$ and $35 \%$ OPC by weight is decreased by $1.91 \%, 2.40 \%, 3.24 \%, 1.90 \%, 3.52 \%$ and $4.87 \%$ respectively. The reason for the density reduction is due to the density of plastic waste, which is less than the density of cement. Hence, the concrete with plastic waste can be used as lightweight concrete and the total weight of the structure will be reduced. However, the density of concrete with $25 \%$ plastic waste as partial replacement of cement is almost similar to $15 \%$ plastic waste replacement. The major factors affecting the densities are the concrete ingredients and compaction. Because of improper compaction, the density behaviour of $25 \%$ plastic waste is different from others. The density of concrete mainly depends on the concrete ingredients and porosity in the concrete. In brief, approximately $1 \%$ to $2 \%$ air content is available in the concrete. Apart from that dry density of cement and polyvinyl chloride are $3150 \mathrm{~kg} / \mathrm{m}^{3}$ and $1300 \mathrm{~kg} / \mathrm{m}^{3}$ respectively. Porosity and density difference are the major reasons for the reduction in density of concrete with various percentages of PVC waste.

Table 3. Wet and dry densities of plastic cement concrete

\begin{tabular}{cccc}
\hline Plastic waste replacement in $\%$ & Wet density, $/ \mathrm{cm}^{3}$ & Dry density, $\mathrm{g} / \mathrm{cm}^{3}$ & Decrease in density (\%) \\
\hline 0 & 2.155 & 2.114 & 1.91 \\
15 & 2.087 & 2.037 & 2.40 \\
20 & 1.983 & 1.919 & 3.24 \\
25 & 2.051 & 2.012 & 1.90 \\
30 & 1.962 & 1.893 & 3.52 \\
35 & 1.970 & 1.874 & 4.87 \\
\hline
\end{tabular}

\subsection{Water absorption}

The water absorption properties of the concrete mix after a curing period of 7 days was determined as indicated in Table 4 . The best water absorption percentage was obtained at a proportion of $35 \%$ plastic waste replacement, this is due to the higher amount of polyvinyl chloride (PVC) resulted in higher surface area availability compared to the Portland cement. Due to this the polyvinyl chloride (PVC) particles will result in partial coverage of partial aggregate surface and left some empty spaces. 
Table 4. Water absorption properties of plastic cement

\begin{tabular}{ccccccc}
\hline Plastic waste replacement (\%) & 0 & 15 & 20 & 25 & 30 & 35 \\
\hline Water Absorption (\%) & 1.92 & 0.98 & 3.20 & 1.93 & 3.52 & 5.86 \\
\hline
\end{tabular}

Water absorption property of the concrete with $25 \%$ plastic waste as partial replacement of cement is lesser than the $20 \%$ plastic waste. There established a relation between concrete compaction and voids in the concrete. Because of improper compaction, the water absorption behaviour of $25 \%$ plastic waste is different from others.

\subsection{Compressive strength test}

The compressive strength of the produced concrete mix of grade C30 was tested after a specified curing period and the results are shown in Table 5. Table 5 indicates that the compressive strength ranges from 21.64 to $12.22 \mathrm{MPa}$ for $0 \%$ to $35 \%$ mix respectively. The 7 days curing could reduce the compressive strength by $20-30 \%$ of the real concrete strength when it was kept for a curing period of 28-day. Therefore, the optimum compressive strength in this test must be kept in the range of 21-24 MPa rather than $30 \mathrm{MPa}$. The results showed that the compressive strength of the plastic cement exhibited a decreasing trend for an increase in percentages of polyvinyl chloride in the concrete mix. The compressive strength of concrete is depending upon the density of concrete ingredients and additives. The density of plastic waste is lesser than the density of cement. And hence, the compressive strengths of concrete with higher percentages of PVC are reduced when compared to the control mix without any plastic waste. The maximum forces applied to varying compositions of plastic waste are indicated in Table 5. As shown, there is a difference in the strength of the cubes of the same percentage. This may be due to error occurred during the process of mixing, compaction type, type of cement used, quality of the aggregate used, and curing days ( 7 days).

Table 5. Maximum force \& compressive strength of the produced concrete mix

\begin{tabular}{|c|c|c|}
\hline Plastic waste replacement & Maximum force $(\mathrm{kN})$ & Average Compressive strength (MPa) \\
\hline \multirow{3}{*}{$0 \%$} & 536.5 & \multirow{3}{*}{21.64} \\
\hline & 486.9 & \\
\hline & 437.5 & \\
\hline \multirow{2}{*}{$15 \%$} & 419.8 & \multirow{2}{*}{19.25} \\
\hline & 446.5 & \\
\hline \multirow{3}{*}{$20 \%$} & 246.8 & \multirow{3}{*}{15.18} \\
\hline & 336.6 & \\
\hline & 441.2 & \\
\hline \multirow{3}{*}{$25 \%$} & 283.9 & \multirow{3}{*}{16.77} \\
\hline & 433.7 & \\
\hline & 414.3 & \\
\hline \multirow{3}{*}{$30 \%$} & 253.4 & \multirow{3}{*}{12.40} \\
\hline & 301.3 & \\
\hline & 282.3 & \\
\hline \multirow{3}{*}{$35 \%$} & 291.0 & \multirow{3}{*}{12.22} \\
\hline & 239.7 & \\
\hline & 294.2 & \\
\hline
\end{tabular}




\subsection{Characterization using XRD}

The XRD analysis was employed to evaluate the crystalline structure of polyvinyl chloride (PVC) with a diffraction angle (2q) ranging from $10^{\circ}$ to $90^{\circ}$. The diffraction pattern of polyvinyl chloride (PVC) is shown in Figure 4. The highest diffraction peak was observed at a diffraction angle of $24.4^{\circ}$ and intensity corresponding to 422 counts. Figure 5 to Figure 10 represents the X-Ray diffraction spectra of the concrete mixes at varying proportions of PVC (i.e. from $0 \%$ PVC to $35 \%$ PVC). Strong diffraction peaks were seen in the spectra and the peak intensity was observed at $30.60^{\circ}$ for $0 \%$ mix, $48.4^{\circ}$ for $15 \%$ mix, $54.16^{\circ}$ for $20 \%$ mix, $61.2^{\circ}$ for $25 \%$ mix, $30.16^{\circ}$ for $30 \%$ mix and $29.20^{\circ}$ for $35 \%$ mix respectively.

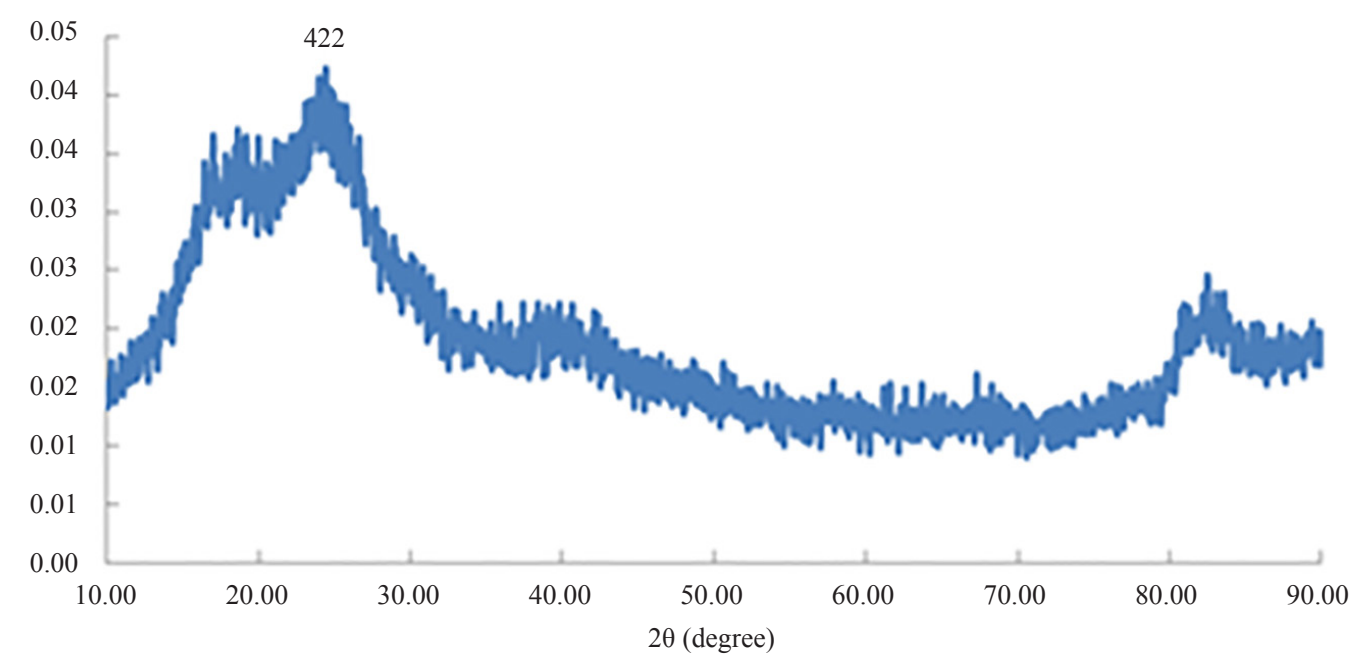

Figure 4. X-ray diffraction pattern of PVC

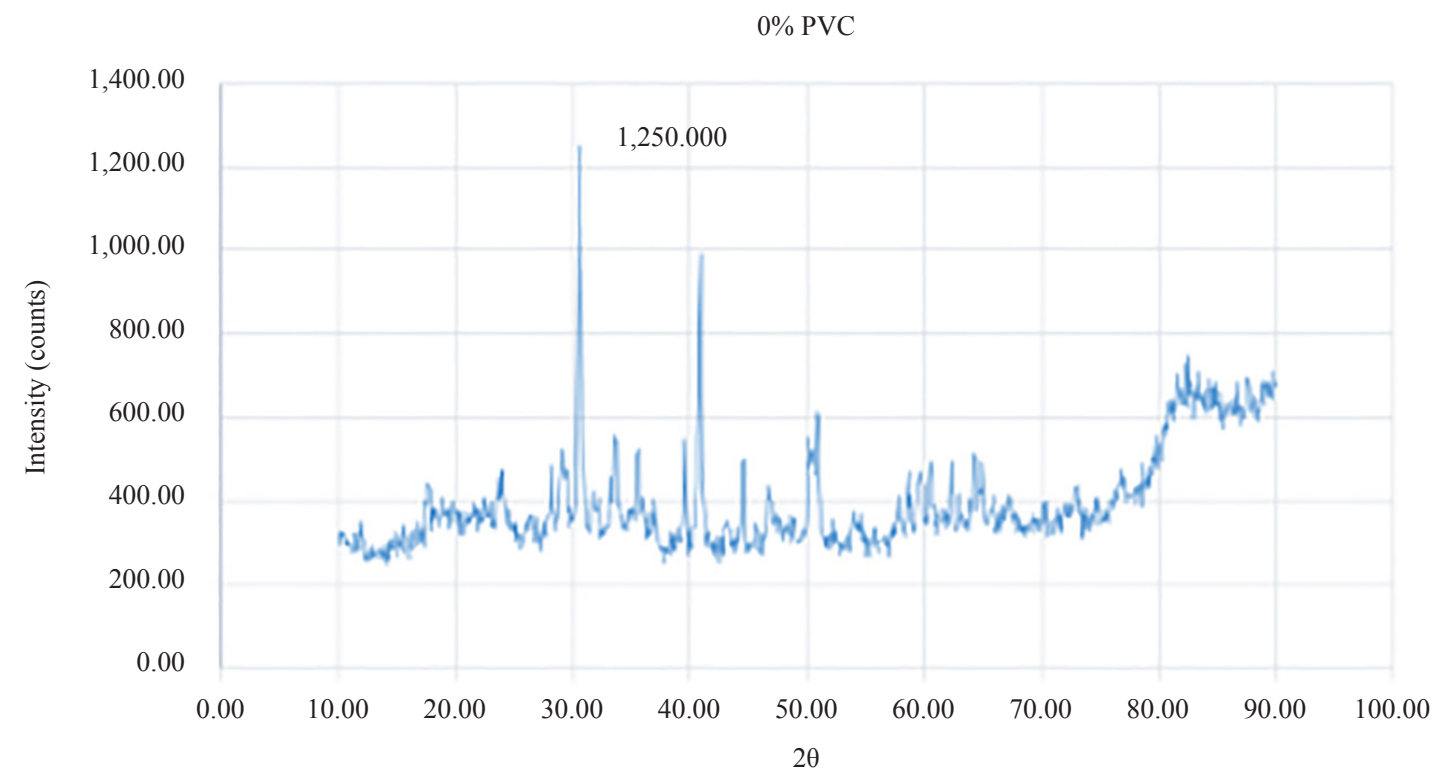

Figure 5. X-ray diffraction pattem of concrete mix with $0 \% \mathrm{PVC}$ 
$15 \%$ PVC

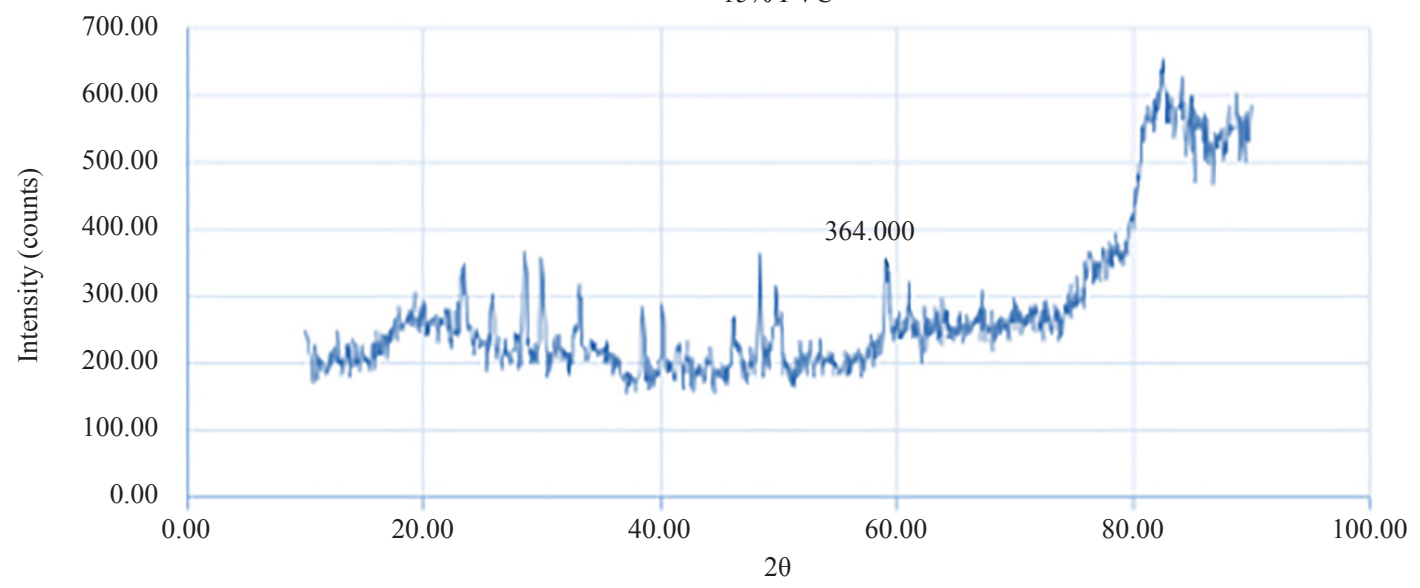

Figure 6. X-ray diffraction pattem of concrete mix with $15 \%$ PVC

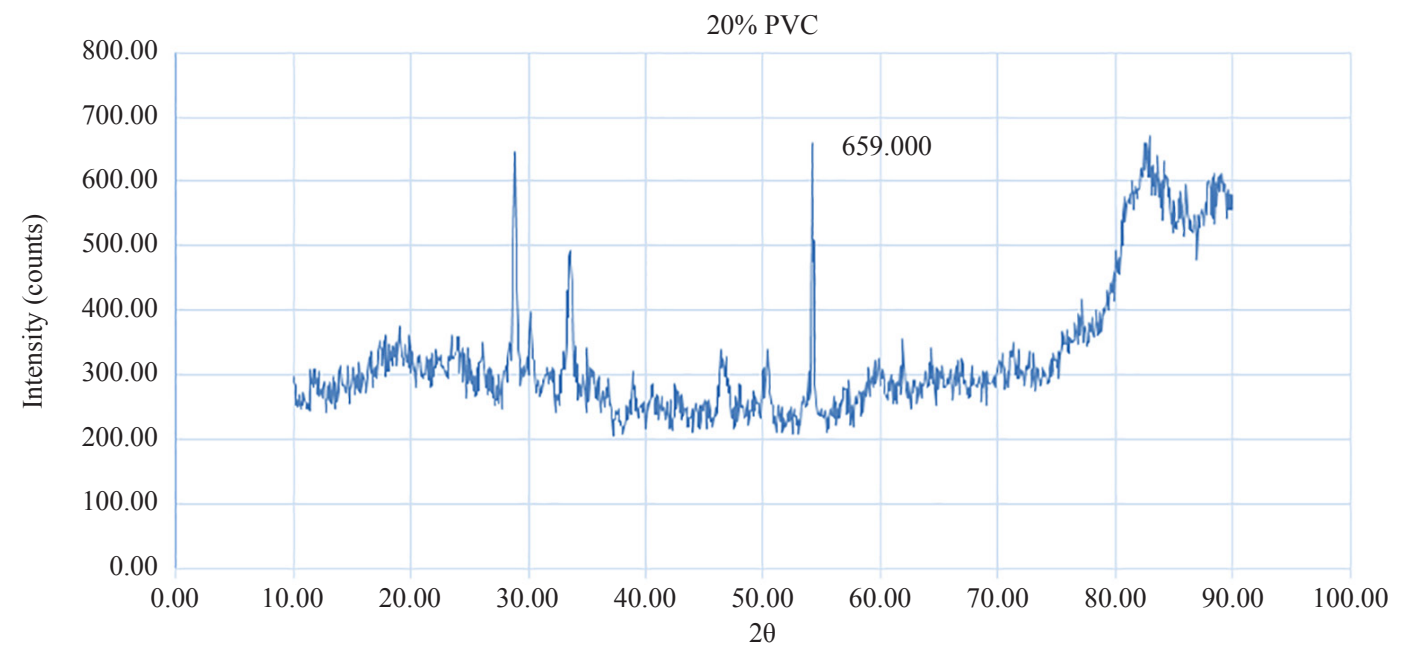

Figure 7. X-ray diffraction pattem of concrete mix with $20 \%$ PVC

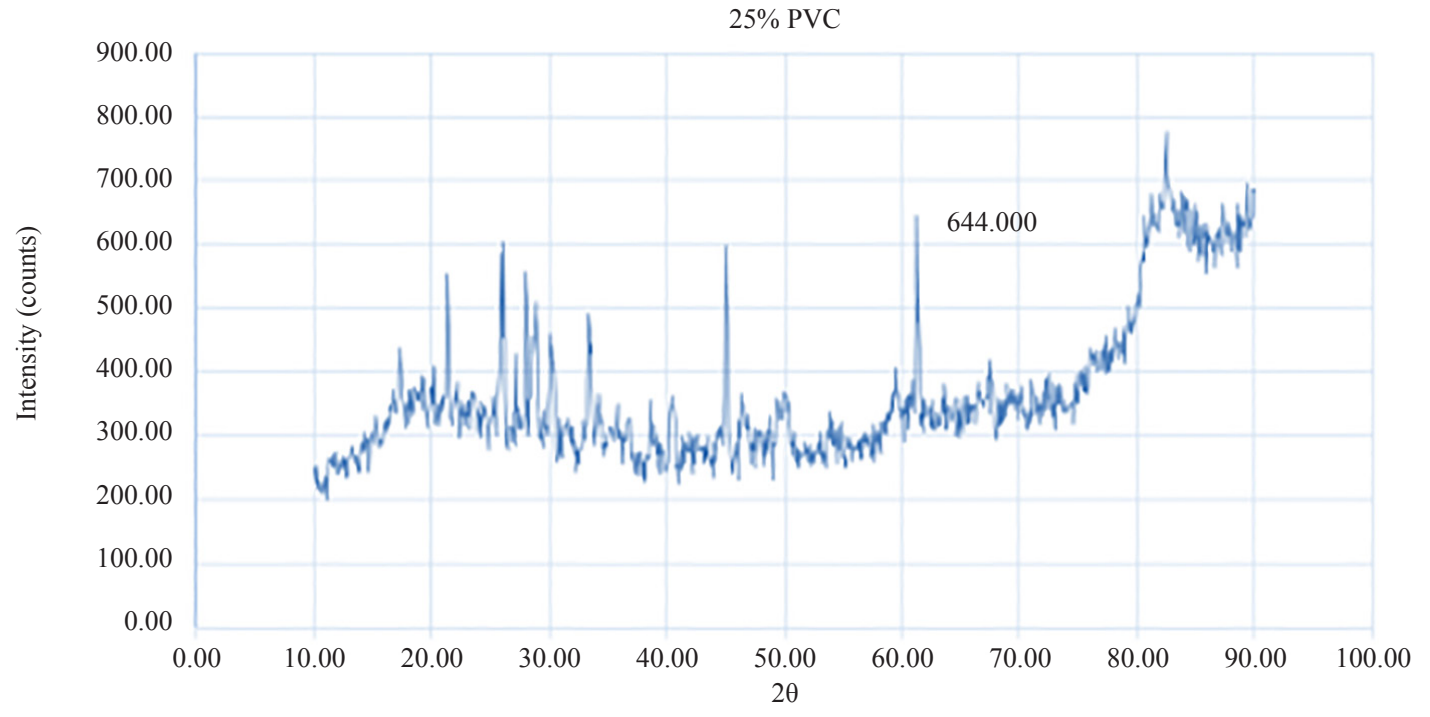

Figure 8. X-ray diffraction pattem of concrete mix with $25 \%$ PVC 


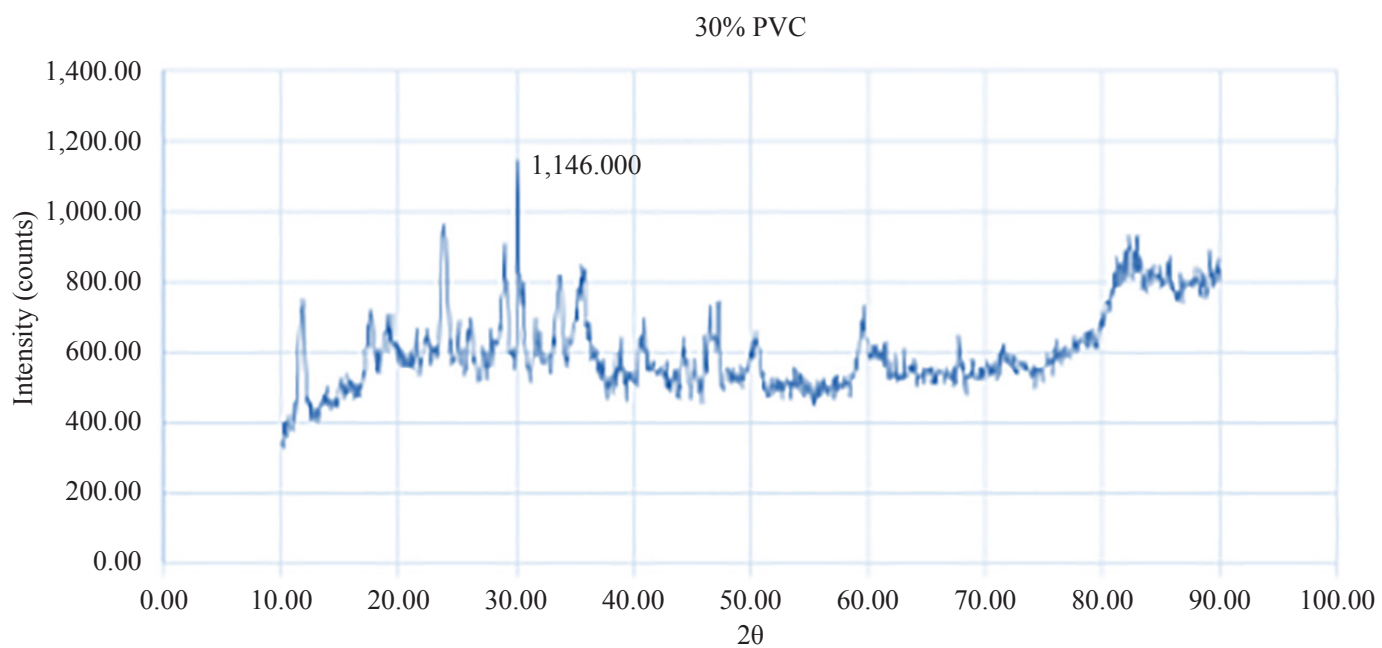

Figure 9. X-ray diffraction pattem of concrete mix with $30 \%$ PVC

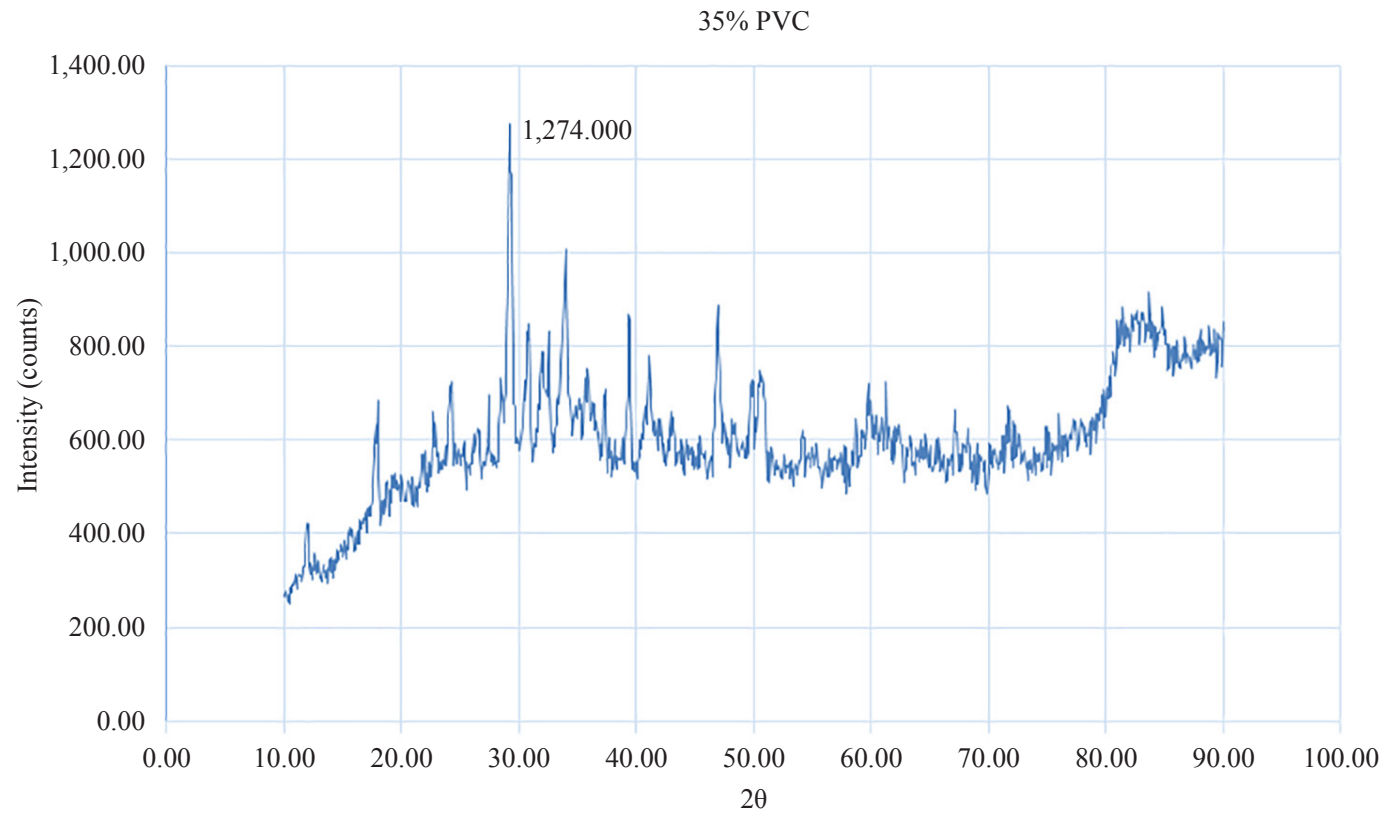

Figure 10. X-ray diffraction pattern of concrete mix with $35 \%$ PVC

The intensity has highest and reached approximately 1250 counts at $30.60^{\circ}$ for $0 \%$ mix, 364 counts at $48.4^{\circ}$ for $15 \%$ mix, 659 counts at $54.16^{\circ}$ for $20 \%$ mix, 644 counts at $61.2^{\circ}$ for $25 \%$ mix, 1146 counts at $30.16^{\circ}$ for $30 \%$ mix and 1274 counts at $29.20^{\circ}$ for $35 \%$ mix.

\subsection{Fourier-Transform Infrared Spectroscopy (FTIR)}

FTIR spectroscopic analysis provided the properties of concrete mix and in-situ monitoring of hydration reactions. Figure 11 shows the FTIR spectra and characteristic absorbance bands of pure polyvinyl chloride. The spectroscopic analysis was conducted at room temperature with wavenumber ranges from $4000 \mathrm{~cm}^{-1}-400 \mathrm{~cm}^{-1}$. The FTIR analysis showed a stretching vibration of $\mathrm{SiO}_{4}$ tetrahedra for slag at $956 \mathrm{~cm}^{-1}$. 
$25 \%$ PVC

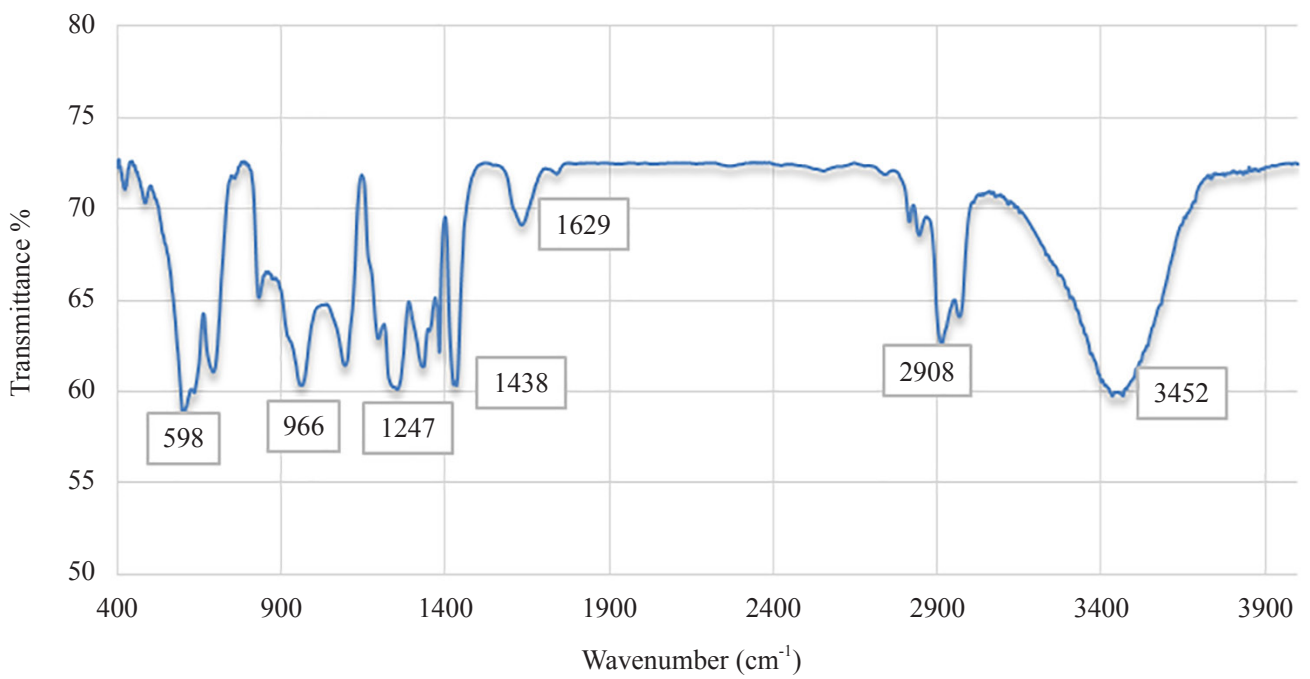

Figure 11. FTIR spectra of PVC

In Figure 11, the absorption peak of polyvinyl chloride (PVC) was found at the wave numbers corresponding to $1438 \mathrm{~cm}^{-1}$ and $3452 \mathrm{~cm}^{-1}$ associated with the expansion mode of $\mathrm{O}-\mathrm{H}$ vibration and $598 \mathrm{~cm}^{-1}$ is associated with the expansion mode of $\mathrm{C}-\mathrm{Cl}$ vibration, and $2908 \mathrm{~cm}^{-1}$ is associated with the expansion of $\mathrm{C}-\mathrm{H}$. The absorption peak of $\mathrm{Ca}(\mathrm{OH})_{2}$ is caused by the stretching vibration of $\mathrm{O}-\mathrm{H}\left(3641-3644 \mathrm{~cm}^{-1}\right)$

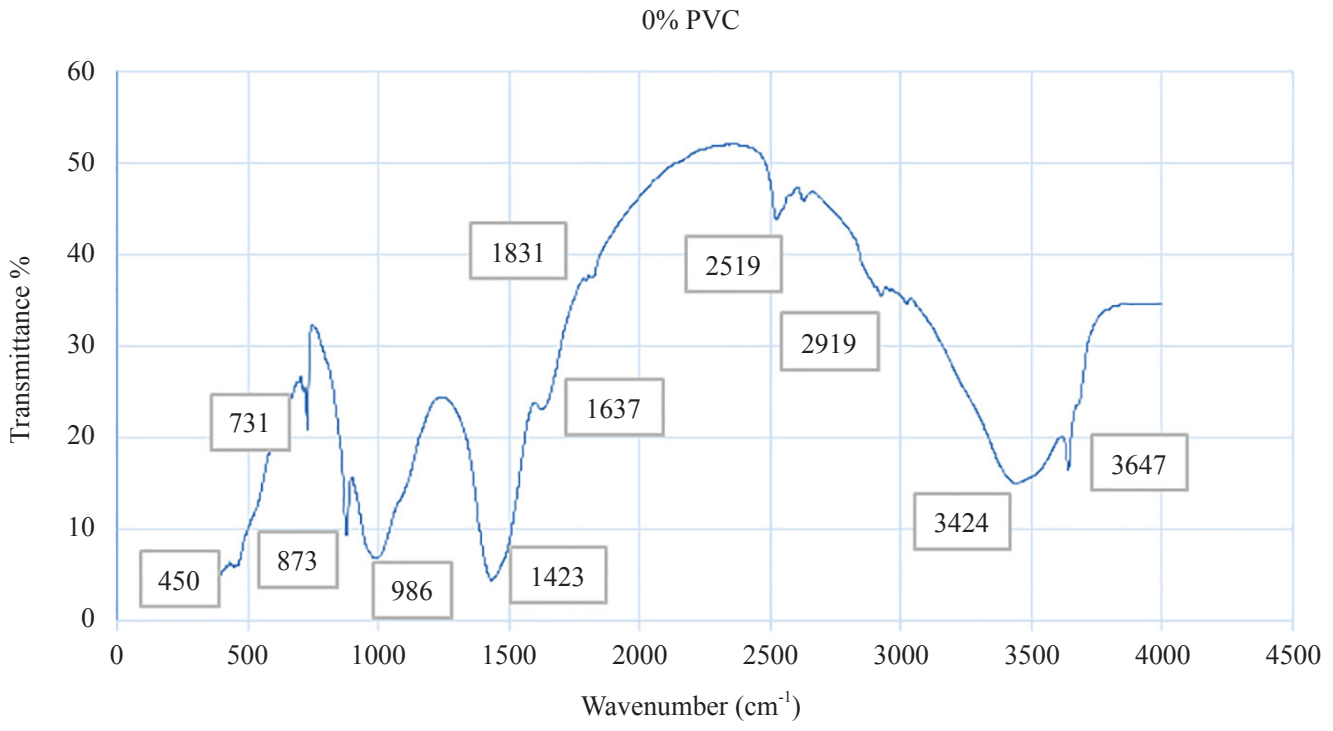

Figure 12. FTIR spectra of concrete mix 0\% PVC

In Figure 12 the absorption peak of polyvinyl chloride (PVC) in the $0 \%$ mix was established at a wave number corresponding to $1423 \mathrm{~cm}^{-1}$ and at $3424 \mathrm{~cm}^{-1}$ associated with the expansion mode of O-H and $986 \mathrm{~cm}^{-1}$ is associated with the expansion mode of $\mathrm{C}=\mathrm{C}$. The bands at $3390-3408 \mathrm{~cm}^{-1}$ and $1640-1650 \mathrm{~cm}^{-1}$ are due to the stretching vibrations and bending vibration of $\mathrm{H}_{2} \mathrm{O}$, respectively. The bands in the $1400-1500 \mathrm{~cm}^{-1}$ range correspond to the asymmetric stretching of $\mathrm{CO}_{3}{ }^{2-}$. 


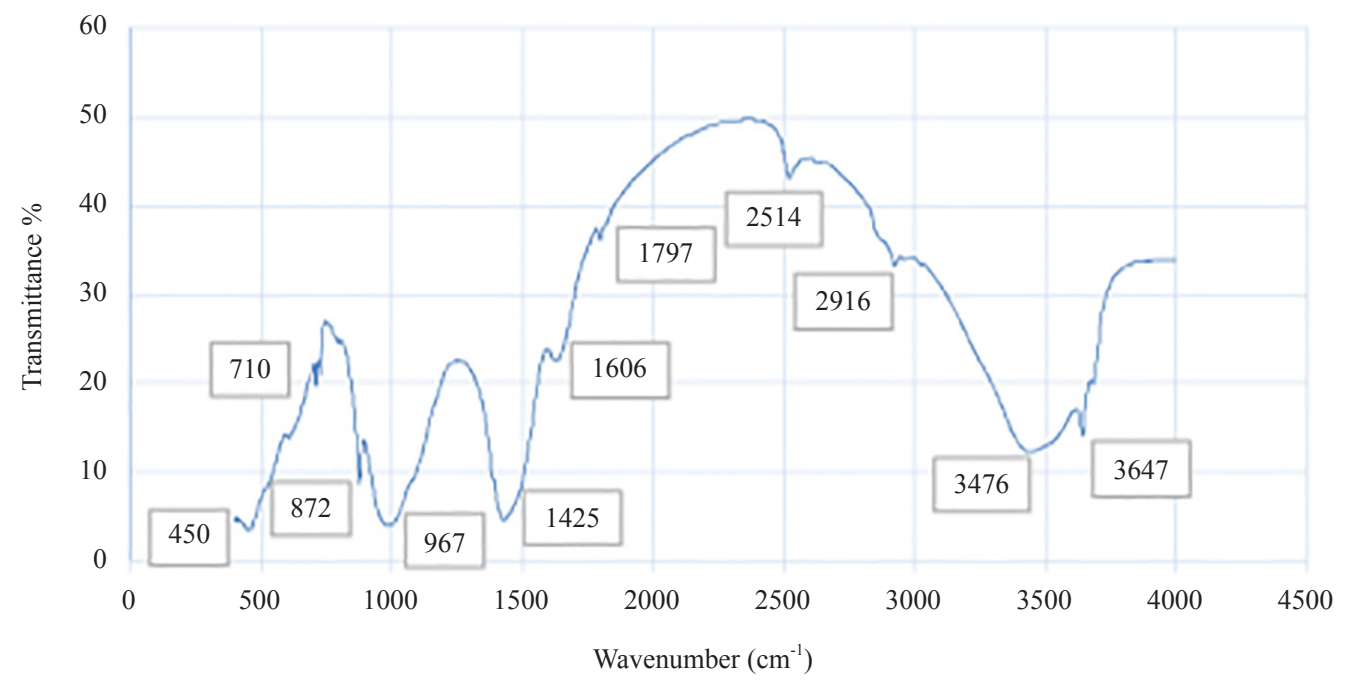

Figure 13. FTIR spectra of concrete mix with $15 \%$ PVC

In Figure 13 the absorption peak of polyvinyl chloride (PVC) in the $15 \%$ mix was observed at a wave number corresponding to $1425 \mathrm{~cm}^{-1}$ and another peak at $3476 \mathrm{~cm}^{-1}$ associated with the expansion mode of $\mathrm{O}-\mathrm{H}$, and $967 \mathrm{~cm}^{-1}$ is associated with the expansion mode of $\mathrm{C}=\mathrm{C}$.

$20 \%$ PVC

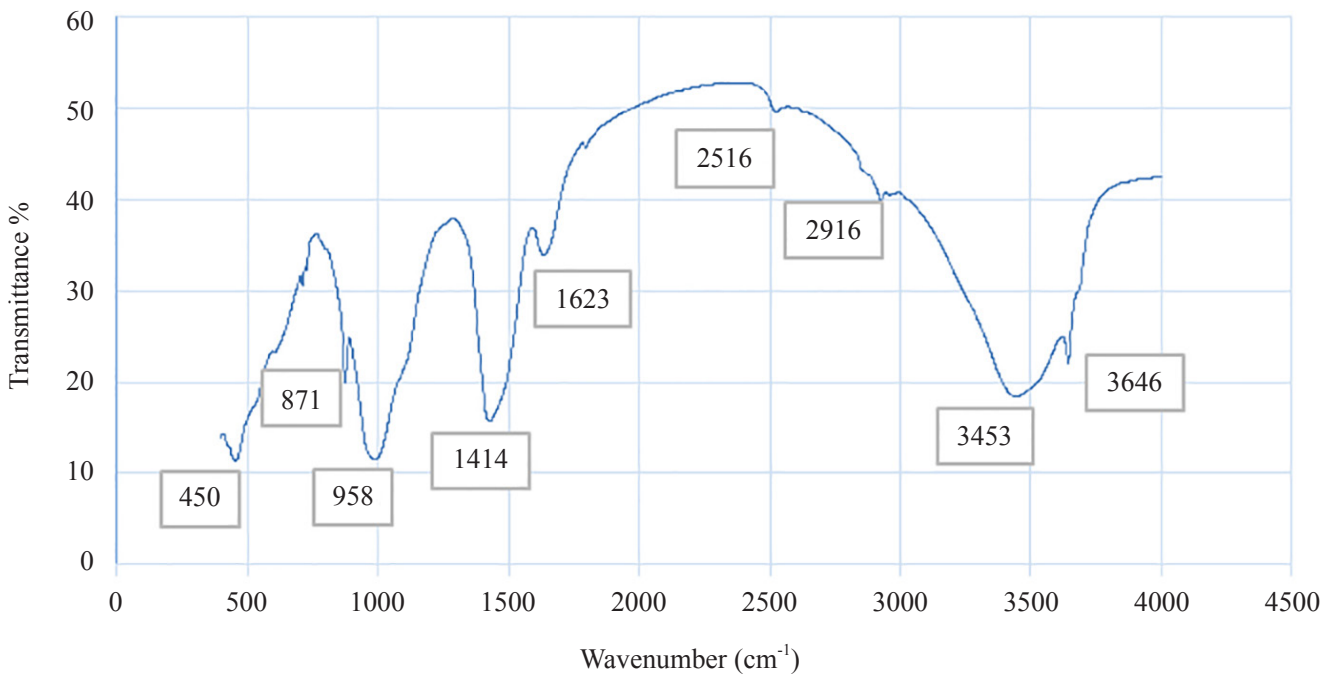

Figure 14. FTIR spectra of concrete mix with $20 \%$ PVC

Figure 14 showed the absorption peak of polyvinyl chloride (PVC) for the $20 \%$ mix was found at a wavenumber of $1414 \mathrm{~cm}^{-1}$ and the second peak at $3453 \mathrm{~cm}^{-1}$ associated with the expansion mode of O-H and $871 \mathrm{~cm}^{-1}$ is associated with the expansion mode of $\mathrm{C}-\mathrm{H}$. 


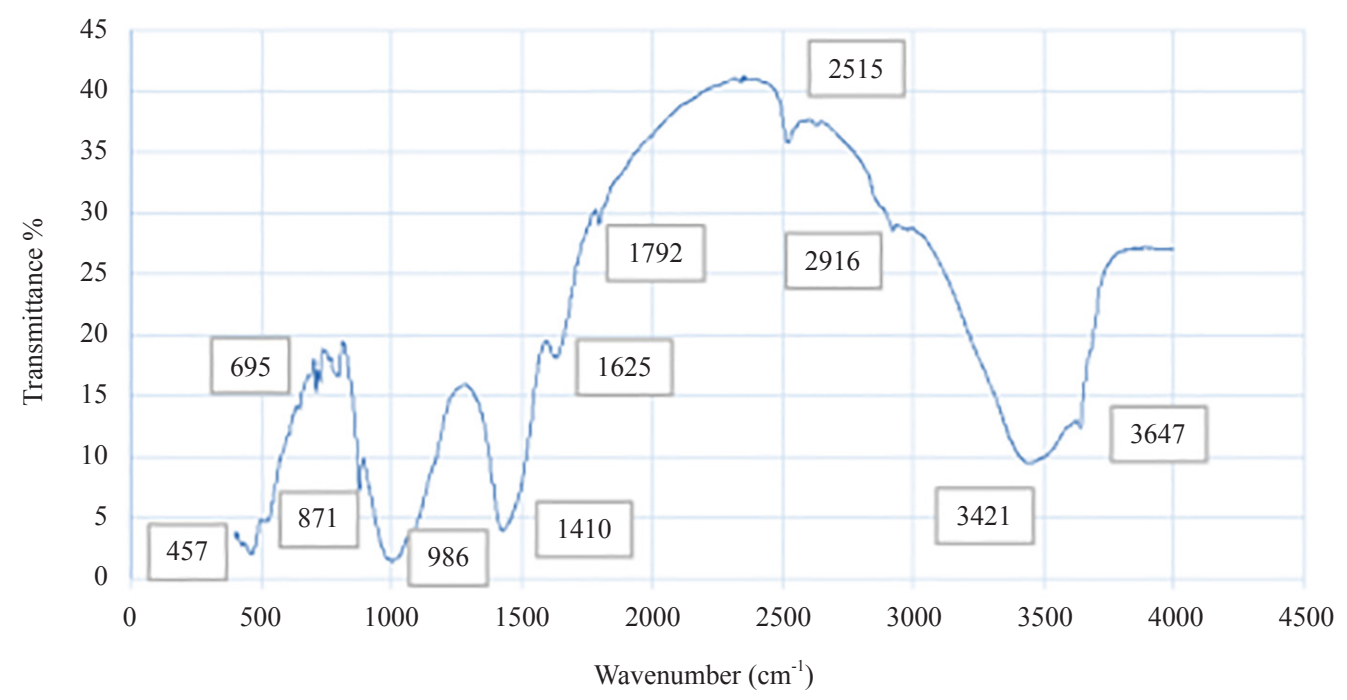

Figure 15. FTIR spectra of concrete mix with $25 \%$ PVC

In Figure 15 above the absorption peak of polyvinyl chloride (PVC) in the $25 \%$ mix is founded in the wavenumber $1410 \mathrm{~cm}^{-1}$ and $3421 \mathrm{~cm}^{-1}$ associated with the expansion mode of $\mathrm{O}-\mathrm{H}$ and $986 \mathrm{~cm}^{-1}$ is associated with the expansion mode of $\mathrm{C}=\mathrm{C}$.

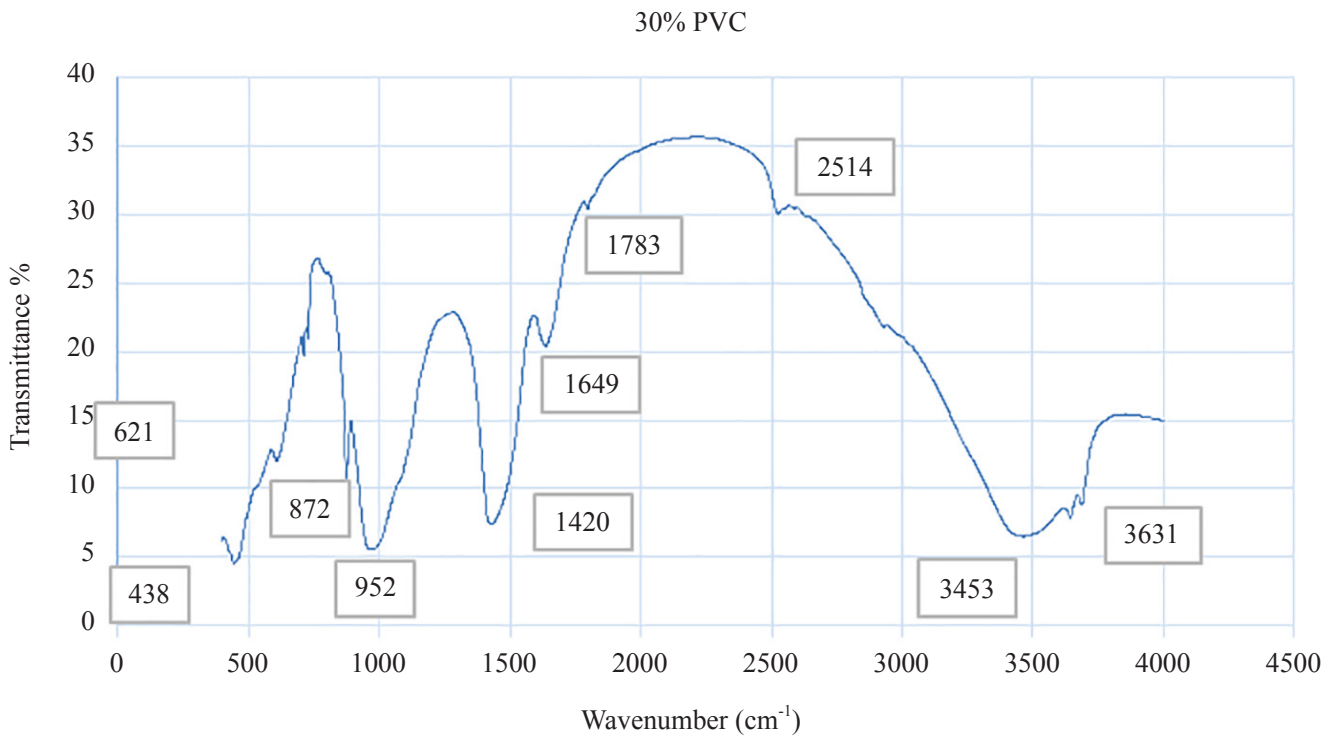

Figure 16. FTIR spectra of concrete mix with $30 \%$ PVC

The peak observed in Figure 16 indicates the absorption peak of polyvinyl chloride (PVC) in the 30\% mix at a wavenumber of $1420 \mathrm{~cm}^{-1}$ and $3453 \mathrm{~cm}^{-1}$ associated with the expansion mode of $\mathrm{O}-\mathrm{H}$ and $1649 \mathrm{~cm}^{-1}$ is associated with the expansion mode of $\mathrm{C}=\mathrm{C}$. 


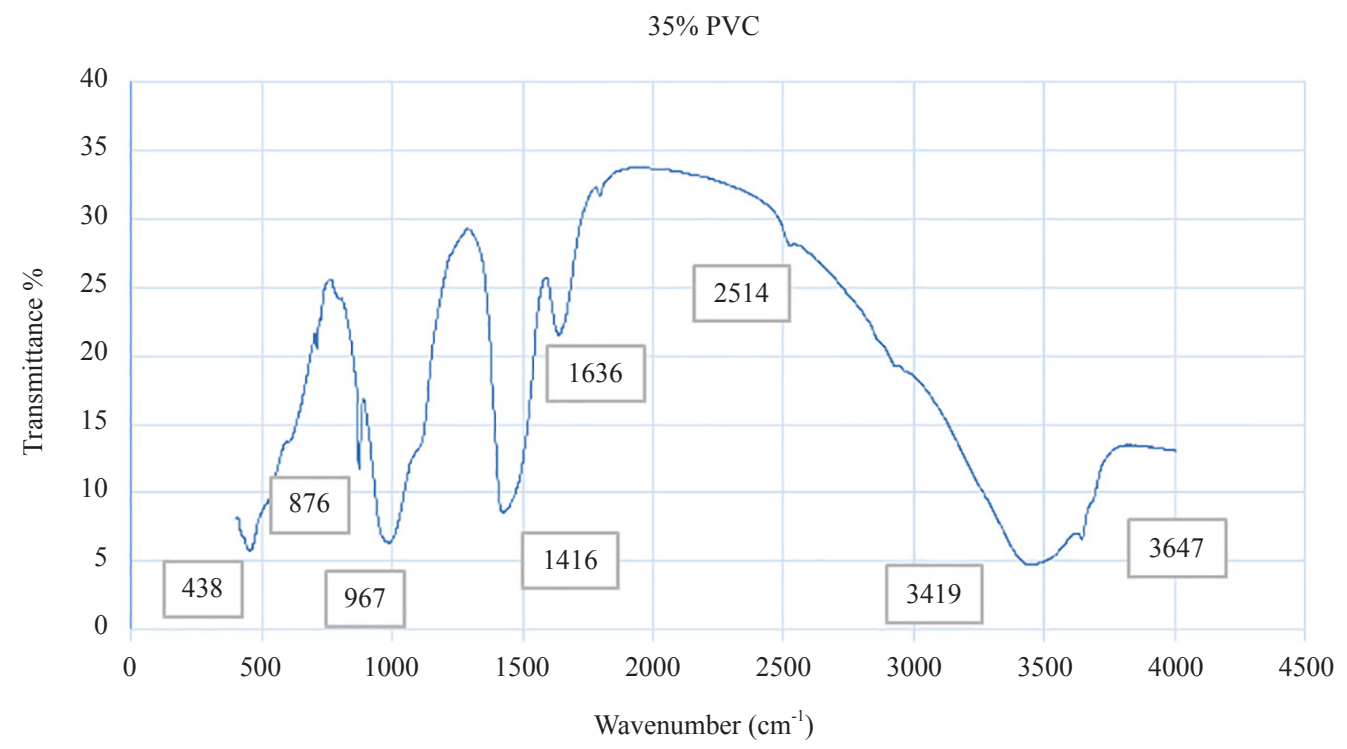

Figure 17. FTIR spectra of concrete mix with $35 \%$ PVC

In Figure 17, the absorption peak of polyvinyl chloride (PVC) in the $35 \%$ mix was found at wavenumbers corresponding to $1416 \mathrm{~cm}^{-1}$ and $3419 \mathrm{~cm}^{-1}$, which are associated with the stretching vibration of $\mathrm{O}-\mathrm{H}, 967 \mathrm{~cm}^{-1}$ is associated with the expansion of $\mathrm{C}=\mathrm{C}$ and $876 \mathrm{~cm}^{-1}$ is associated with the expansion mode of C-H. Fourier transforms infrared spectroscopy analysis indicates that the PVC powder has a physical effect (i.e., nucleation effect and dilution effect) on cement hydration and also it contributes a chemical effect (i.e., chemical reaction).

\subsection{Statistical analysis}

Statistical analysis was carried out for compressive strength tests. Error bar shows the minimum and maximum values in a ranged dataset. For the statistical analysis, 95\% confidence levels are considered for control mix and concrete with various percentages of plastic wastes. Table 6 shows the mean, variance, standard deviation and standard error of the mean values for compressive strength tests for all the mixes. The ' $z$ ' score for $95 \%$ confidence level is 1.96 . Figure 18 shows the compressive strength test results of all the cube specimens with error bars.

Table 6. Descriptive statistics of compressive strength test results

\begin{tabular}{ccccccc}
\hline \multirow{2}{*}{ Descriptive Statistics } & \multicolumn{5}{c}{ Compressive Strength in MPa } \\
\cline { 2 - 7 } & $0 \%$ & $15 \%$ & $20 \%$ & $25 \%$ & $30 \%$ & $35 \%$ \\
\hline Mean & 21.64 & 19.25 & 15.18 & 16.77 & 12.4 & 12.22 \\
Variance & 4.839 & 0.696 & 18.699 & 13.106 & 1.151 & 1.854 \\
Standard Deviation & 2.199 & 0.834 & 4.324 & 3.62 & 1.073 & 1.362 \\
Standard Error of the Mean & 1.270 & 0.590 & 2.496 & 2.090 & 0.619 & 0.786 \\
Margin of Error (95\% CF) & \pm 2.488 & \pm 1.156 & \pm 4.893 & \pm 4.096 & \pm 1.214 & \pm 1.541 \\
\hline
\end{tabular}




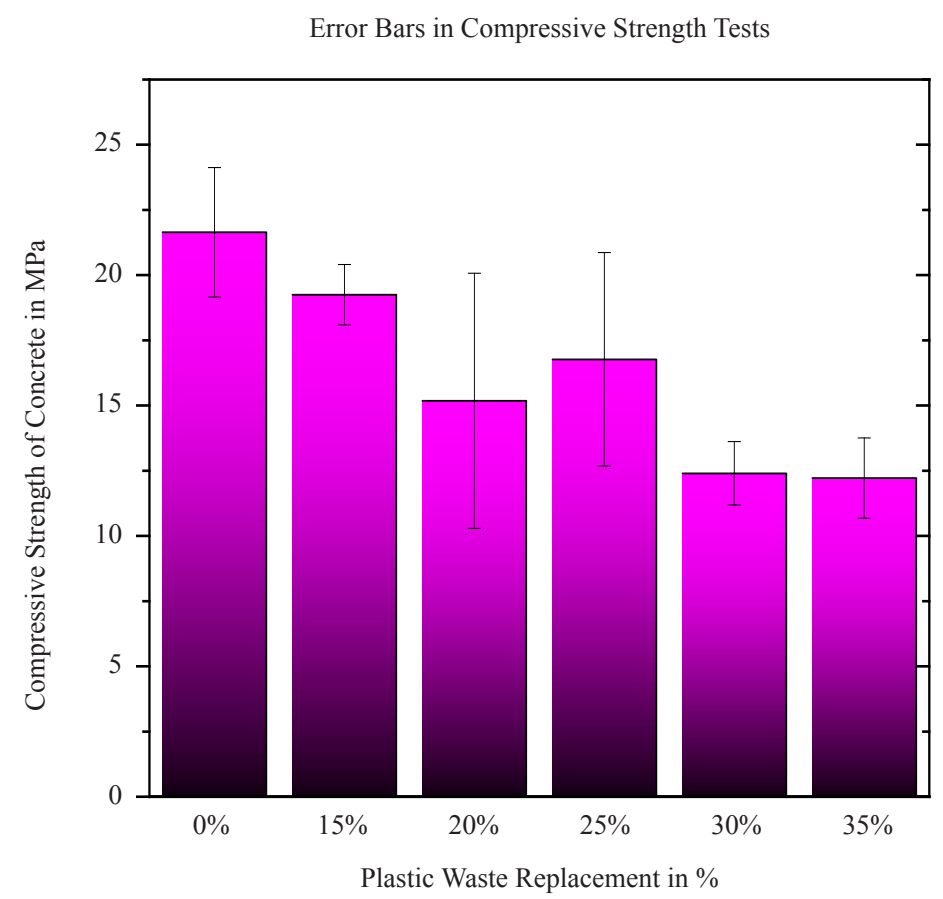

Figure 18. Compressive strength test results with error bars

\section{Conclusion}

Plastic processing industry is one of the major pollution-causing industries in the country. This research attempted to assess the application of polyvinyl chloride discarded from the plastic-pipe manufacturing industry for producing plastic cement in an environmental-friendly and economical method. The partial replacement of the OPC by polyvinyl chloride offers an eco-friendly way to produce plastic cement. The experimental results indicate that Portland cement could partially be replaced with waste polyvinyl chloride in the varying percentages of $15 \%, 20 \%, 25 \%, 30 \%$ and $35 \%$ respectively. The results show that the density of the mixes increases with an increase in PVC composition up to $25 \%$ mix and then decreased. The maximum density of $2.051 \mathrm{~g} / \mathrm{cm}^{3}$ is observed at $25 \%$ concrete mix. The water absorption capacity is maximum $(5.86 \%)$ at a concrete mix percentage of $35 \%$. The optimum compressive strength of the concrete mix is established at $15 \%$ concrete mix by $19.25 \mathrm{MPa}$. The results demonstrate that polyvinyl chloride has the capability to replace cement by $15 \%$ (weight) slightly less than that of control mix. Moreover, the results are confirmed through Fourier Transform Infra-Red Spectroscopy and X-ray Diffraction analyses. The study recommends the prospects of using waste polyvinyl chloride as an alternative to partial replacement of OPC with eco-friendly binding material in normal environmental conditions. The seven-day compressive strength of concrete is normally $60 \%$ of the 28 -day strength and for $\mathrm{C} 30$ grade concrete it should be more than $18 \mathrm{MPa}$. Based on the experimental results, the seven-day compressive strength of concrete with $15 \%$, plastic waste used as partial replacement of cement is, 19.25. Hence, the concrete with plastic waste up to $15 \%$ replacement of cement can be used for the construction of structural members. Concrete with $15 \%$ plastic waste replacement as partial replacement of cement may be used for structural applications. The utilization of waste plastic materials in concrete as a partial aggregate replacement has an obvious effect on the material properties. Reduction in the compressive strength was between $34 \%$ and $67 \%$ for concrete containing $10 \%$ $50 \%$ recycled plastic. Test results of present study prove that the reduction in the compressive strength is between $11.04 \%$ and $43.53 \%$ for concrete containing 15\%-35\% PVC waste. 


\section{Conflict of interest}

The authors declare that they have no conflicts of interest.

\section{References}

[1] Franeker, J.; Blaize, C.; Danielsen, J.; Fairclough, K. Monitoring plastic ingestion by the northern fulmar fulmarus glacialis in the north sea. Environ. Pollut. 2011, 159, 2609-2615.

[2] Ganesh, T.; Satish, P.; Pramod, P.; Hemraj, R.; Kumavat, H. Recycling plastic used in concrete paver block. Int. J. Eng. Res. Technol. 2014, 3, 3335-3342.

[3] Ahmad, K. Recycling of polyethylene waste to produce plastic cement. Procedia Manuf. 2017, 8, 635-642.

[4] Janardhanan, K.; Mohana, E. Experimental study on cement concrete with PVC powder and quarry dust as partial replacement to fine aggregate. IRJET. 2018, 5, 1397-1401.

[5] Akchurina, T.; Tukharelia, V. D.; Pushkarskayaa, Y. The modifying additive for concrete compositions based on the oil refinery waste. Procedia Eng. 2016, 150, 1485-1490.

[6] Vaičiukynienè, D.; Grinys, A.; Vaitkevičius, V.; Kantautas, A. Purified waste FCC catalyst as a cement replacement material. Ceram-Silikaty. 2015, 59, 103-108.

[7] Gettu, R.; Izquierdo, J.; Gomes, P. C. C.; Josa, A. In development of high-strength self-compacting concrete with fly ash: A four-step experimental methodology; Proceedings of 27th conference on our world in concrete and structures, Singapore, 2002.

[8] Grdic, Z. J.; Toplicic-Curcic, G. A.; Despotovic, I. M.; Ristic, N. S. Properties of self-compacting concrete prepared with coarse recycled concrete aggregate. Constr Build Mater. 2010, 24, 1129-1133.

[9] Jawahar, J. G.; Sashidhar, C.; Reddy, I. V. R.; Peter, J. A. Optimization of superplasticizer and viscosity modifying agent in self compacting mortar. Asian J. Civ. Eng. 2013, 14, 71-86.

[10] Behera, M.; Bhattacharyya, S. K.; Minocha, A. K.; Deoliya, R.; Maiti, S. Recycled aggregate from C\&D waste and its use in concrete-A breakthrough towards sustainability in construction sector: A review. Constr Build Mater. 2014, 68, 501-516.

[11] Pereira-de-Oliveira, L. A.; Nepomuceno, M. C. S.; Castro-Gomes, J. P; Vila, M. F. C. Permeability properties of self-compacting concrete with coarse recycled aggregates. Constr Build Mater. 2014, 51, 113-120.

[12] Celik, K.; Meral, C.; Mancio, M.; Mehta, P. K.; Monteiro, P. J. M. A comparative study of self-consolidating concretes incorporating high volume natural Pozzolan or high volume fly ash. Constr Build Mater. 2014, 67, 14-19.

[13] Al-Bahar, S.; Chakkamalayath, J.; Joseph, A.; Abdulsalam, M.; AlOtaibi, S.; Al-Aibani, A. Effect of volcanic ash incorporation on the mechanical properties and surface morphology of hydrated cement paste. J. Mater. Civ. Eng. 2017, 29, 1943-5533.

[14] Al-Fadala, S.; Chakkamalayath, J.; Al-Bahar, S.; Al-Aibani, A.; Ahmed, S. Significance of performance based specifications in the qualification and characterization of blended cement using volcanic ash. Constr Build Mater. 2017, 144, 532-540.

[15] Baboo Rai, S.; Tabin, R.; Bhavesh, K.; Duggal, B. K. Study of waste plastic mix concrete with plasticizer. ISRN Civ. Eng. 2012, 1, 1-5.

[16] Pramod, S. P. Behavior of concrete which is partially replaced with waste plastic. IJITEE. 2015, 4, 1-3.

[17] Hanifi, B. Effect of aggregate type on mortars without cement. EJET. 2013, 1, 1-6.

[18] James, R. M.; Julie beth, Z. Environment, Sustainable design; John Weley and Sons Inc., 2010; pp 236-24.

[19] Batayneh, M.; Marie, I.; Asi, I. Use of selected waste materials in concrete mixes. Waste Manage. 2007, 27, 18701876.

[20] Choi, Y. W.; Moon, D. J.; Chung, J. S.; Cho, S. K. Effects of waste PET bottles aggregate on the properties of concrete. Cem Concr Res. 2005, 35, 776-781.

[21] Marzouk, O. Y.; Dheilly, R. M.; Queneude, M. Valorisation of post-consumer waste plastic in cementitious concrete composites. Waste Manage. 2007, 27, 310-318.

[22] Rebeiz, K. S. Precast use of polymer concrete using unsaturated polymer resin based on recycled PET waste. Constr Build Mater. 1996, 10, 215-220.

[23] Binici, H.; Gemci, R.; Kaplan, H. Physical and mechanical properties of mortar without cement. Constr Build Mater. 2012, 28, 357-36.

[24] Aravind, N.; Abdulrehman, T. I. A review and sequel experimental analysis on physical and mechanical properties 
of permeable concrete for pavement construction. Int. J. Pavement Eng. 2021, 22, 1936519.

[25] Sifatullah, B.; Safiullah, O.; Francoise, F.; Amanullah, F. Fresh and hardened properties of concrete containing different forms of plastic waste-A review. Waste Manage. 2020, 113, 157-175.

[26] Castillo, E. R.; Almesfer, N.; Saggib, O.; Ingham, J. M. Light-weight concrete with artificial aggregate manufactured from plastic waste. Constr Build Mater. 2020, 265, 120199.

[27] Mustafa, M. A.; Abdullah, M. Z.; Osama, D.; Tayeh, B. A. Experimental and numerical investigations of the influence of partial replacement of coarse aggregates by plastic waste on the impact load. Int. J. Sustain. Eng. 2021, $14,1-8$

[28] Ravikumar, K.; Ranjini, A.; Ayappan, A.; Kumar, R. Experimental investigation on concrete using polyvinyl chloride pipes. IJEERT. 2019, 5, 60-68.

[29] Kolhapure, B.; Chavan, A.; Irshad, A.; Amar, B.; Patel, H. Eco-friendly concrete by partial replacement of sand by shredded pieces of PET plastic bottles. IRJET. 2018, 5, 1259-1263.

[30] Shadrack, M.; Sabai, M.; Bertha X. Recycling of oil sludge together with construction and demolition waste into building materials in Tanzania. Afr. J. Environ. Sci. Technol. 2018, 12, 84-90. 